\title{
Research on the Relations between Network Diversity and Innovation Performance of Small Technological Enterprises---- Moderating Effect of Technological Turbulence
}

\author{
Yi LI ${ }^{1, a}$, Qiu-Yan TAO ${ }^{1, b,}$, Run-Han YUE ${ }^{1, c}$ \\ ${ }^{1}$ North Fourth Ring Road, Chaoyang District, Beijing No. 97, Beijing Union University, China \\ a446455191@qq.com, bqiuyan@buu.edu.cn, ${ }^{c} 18810915966 @ 163 . c o m$
}

\begin{abstract}
Key words: Small Enterprise, Social Network Diversity, Innovation Performance, Technical Environment Turbulence.
\end{abstract}

\begin{abstract}
With the deepening of social network research, network diversity has been paid more and more attention. Based on the current background of China, this paper uses the main theories and methods of social network research to explore the impact of the diversity of small enterprises' social network on innovation performance in China. First of all, analyzes the main status of cooperation of small enterprises and their social network from the inter-organizational interaction level; On this basis, put forward the hypothesis model of " social network diversity of small enterprise negatively impact on innovation performance and technological environment turbulence play a regulatory role between them" from the network level; Finally, the use of SPSS and AMOS software for empirical testing, there are two main conclusions to be drew, that social network diversity of small enterprise has a negative impact on innovation performance, and technical environment turbulence weakened such a negative impact.
\end{abstract}

\section{Literature Review}

\section{Network Diversity}

"Network" initially originated in the field of sociology, Brass et al. defined it as a collection of nodes and a collection of representing some kind of relationships between the nodes. With the application and development of social networks, there are a series of theories to be produced, such as Weak Joint Advantage Theory[19], Mosaic Theory[20]and Structural Hole Theory[21], are used to explain the network phenomenon. Many scholars, from the "strong and weak relationship" or "structural hole" angle, analysis of the enterprise social network, Academia known as "the dispute between strong and weak relationship" and "the dispute of structural hole ", However, relative to the strong and weak relationships and structural holes, the study of network diversity is still inadequate, although the network diversity is also an important dimension of the network.

According to the scholars' research, the nature of network diversity can be divided into five types: differences in technology, differences in resources and knowledge, differences in the combination of upstream and downstream industry chains, differences in partner complementarity and a combination of four differences above. In this study, the viewpoints of the majority of scholars will define the network diversity as the relative difference between the network members, which is mainly reflected in the degree of differentiation of the network subject in resources, ability, knowledge and technology. Network diversity, as one of the most important features of the network, is an emerging concept.

\section{Innovation Performance}

There are two opposing views on the relationship between network diversity and innovation performance.

A view is that network diversity is conducive to innovation: Reagans \&Zuckerman[22]studies show that network diversity has a search advantage, although network diversity has a negative impact on network density, network strength and network coordination, the diversity increases diversity of perspectives and ideas, and thus enhance the innovation performance. 
Goerzen\&Beamish[1] argues that network diversity gives enterprises a variety of information. On the basis of Transaction Cost and Knowledge Basic Theory, Fang[14] analyzes that the complementarity of knowledge is conducive to innovation and the negative regulatory effect of external environment dynamics between them. Beers C. \& Zand F.[2] found that the organizational diversity of $\mathrm{R} \& \mathrm{D}$ partners is positively related to breakthrough innovation.

Another view is that network diversity adversely affects innovation: Goerzen \& Beamish[1] argues that network diversity increases complexity and coordination costs. Cajueiro \& Tabak[3] et al, through the analysis of the Brazilian inter-bank network, pointed out that the higher the degree of interconnection between the networks, the greater the industry risk. Tiwana[4] argues that the creation potential of redundant knowledge is limited and that knowledge of inter-organizational networks may face a trade-off. Sparse heterogeneity of the network may be obstacles in the transfer of knowledge, if the knowledge cannot be effectively transferred to the enterprise inside, even if the knowledge is novel, it will not have a positive impact on business innovation. Sun GuoQiang and Shi Hairui[5] also put forward a similar point of view, that excessive network embedding also limits the ability of enterprises to acquire external resources, thus weakening the learning ability of enterprises and would not be conducive to the improvement of their innovative performance. Wu Shaotang[6], based on Network Theory and Institutional Theory, considered that network diversification has negative influence on alliance trust and cooperative innovation.

\section{Technology Environmental Turbulence}

About the relationship between network diversity and innovation performance, scholars have come to different conclusions through research. In terms of the reasons, there are two main points: First, the difference of study objects. The size of the enterprise and where the industry has an impact on the results of the study. Second, the difference of study scenarios. Different countries and regions, corporate culture, corporate network environment led to differences in the results of the study. In the social network of small enterprises as the focus of our country, whether the network diversity is conducive to improving the innovation performance of enterprises is a question worth thinking about. In this paper, we study the social network of small enterprises in China, and take into account the important scenario variables of technological environment turbulence, follow the two-dimensional division method of the technology environment turbulence and market environment turbulence produced by Jaworski \& Kohli[18] et al., and select the technology environmental turbulence as a regulated variable in this study.

Above all, what kind of impact does social network diversity of small enterprise has on its innovation performance is worth exploring, and technical environment turbulence is added as regulated variable make the study more refined and the results are more convincing.

\section{Conceptual Model and Assumptions}

\section{Conceptual Model}

This paper analyzes the cooperation between the small enterprise and its social network subjects from the organizational level; then it analyzes the influence of the network diversity on the innovation performance from the whole network level; finally it analyzes the adjustment of the technological environment turbulence between the network diversity and the innovation performance. According to the definition of innovation network of small and medium-sized enterprises produced by Chi RenYong[23], the small enterprise network defined by this paper refers to the combination of all the interrelations of economic behavior subjects which regard small enterprises as the core. From the perspective of connecting objects, the main body of the network can be divided into seven types which are upstream and downstream enterprises (suppliers and customers), the same industry enterprises (competitors and complementary enterprises), universities and research institutions, financial institutions, intermediaries, industry associations, and government departments.

And then take small enterprises as the object of study, build the model of small enterprise social 
network diversity on the impact of innovation performance. The diversity of the small enterprise network is the independent variable, the innovation performance is the dependent variable, the technical environment turbulence is the adjustment variable, and discuss the influence of the social network diversity on the innovation performance. At the same time, add control variables may affect the performance of small enterprise such as the enterprise size, corporate age, the nature of ownership, industry and R \& D intensity. Take the "small enterprise" as the object of study and combined with the characteristics of small enterprises may make research more targeted; and introduce situation variable-"technical environment turbulence" may more in line with the current corporate social network environment. Small enterprise network diversity, technical environment turbulence and innovation performance theory model is shown in Fig.1.

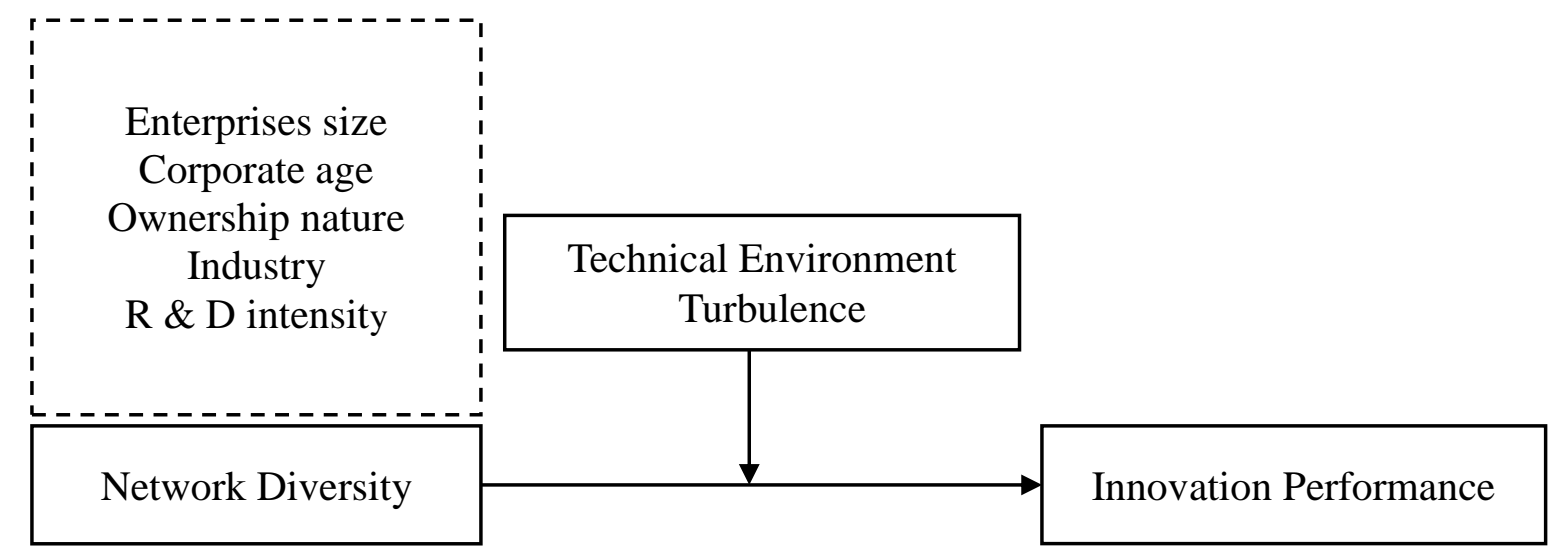

Fig.1. Small enterprise network diversity, technical environment turbulence and innovation performance theory model

\section{Research Hypothesis}

\section{Relations between Network Diversity and Innovation Performance}

Advantages: from the network level, small enterprise network diversity brings many advantages to its innovation:

Network diversity helps enterprises to obtain non-redundant resources from diversified partner organizations and improve innovation efficiency. Higgins \& Kram[24] argues that the higher the degree of diversification provided by the network, the more resources and information with the VR-IN feature that the focus enterprise acquires; Network diversity increased heterogeneity knowledge and will promote multi-disciplinary knowledge synergies[7];Network diversity is conducive to enterprises to obtain complementary resources, to avoid "Core rigidity" or into "Ability traps"; Network diversity has a search advantage, broaden the access to information channels, so that enterprises have a more sensitive knowledge of preamble.

Disadvantages: however, if small enterprises and their social networks in a variety of types of organizations want to establish cooperative relations, they need to pay a certain cost. Small enterprises exchange less experience with their partners, lack of abilities of network supervision to make the innovation process uncontrollable. Frequent flow of innovative flow of the original management system has brought challenges.

The research object of this paper is small enterprise, and the organizations of enterprise social network subjects in this study are more extensive, including upstream and downstream enterprises, industry enterprises, universities and scientific research institutions, financial institutions, industry associations, intermediaries, and government departments such various types of partners. For small enterprises, the diversity of such cooperation can bring a variety of heterogeneous resources, knowledge and channels, but because of limited management capacity, it is difficult to fully absorb and use resources brought about by the network diversity. Bloated network organization disperse energy, high level of diversity make learning more difficult instead, so that lead to the disadvantages of network diversity eventually beyond the advantages. In addition, studies have shown that, at the beginning of innovation activities, business objectives and expectations of innovation income will 
have an impact on corporate innovation decisions. Small enterprises, which are lack of technology, talents, capital and other resources, are more inclined to the pursuit of short-term interests, they obtain price advantages and scale advantages through the compression cost to maximize the operating profit rather than through innovation. In short, combined with the characteristics of small enterprises, the negative impact of innovation brought about by network diversity is greater than the positive aspect.

To sum up, the following assumptions are made: H1 small enterprise social network diversity has negative impact on innovation performance.

\section{Regulatory Role of Technical Environment Turbulence}

Technical environment turbulence: technical environment turbulence refers to the rate of change and degree of technological progress. Technological change, resource competition, increased competition makes the enterprise to face the technical environment uncertainty increases. Studies have shown that the results of network diversity are also related to the external environment in which the enterprise is located. Turbulence level of different technical environment will affect the organizational structure and strategy, effect of exchanging resources, information, and energy between business and external is very different. In this study, using the classical variable of technical environment turbulence to describe the external environment and regard it as a boundary condition for network diversity to be applied to innovation performance. From the level of change, to examine innovation performance trends under varying degrees of the influence of technological environment turbulence.

When the small enterprises in low degree of the technical environment turbulence, the small enterprises, based on the size of enterprises and the status of resources, rational planning, researching and developing, producing core products, can effectively deal with encountered innovation issues with the existing knowledge, technology and capacity. Some other scholars argue that, in a stable environment, due to the existing technology, inertia and behavior patterns rarely out of date, the organization facing the market competition pressure is relatively weak. At this time, the network diversity to the small enterprises increases the burden and disperses the energy, which is not conducive to the improvement of innovation performance.

When the small enterprises in a high degree of the technical environment turbulence, the rapid changes in technology swallowed existing weak knowledge accumulation and resource endowment in the small enterprise, brought pressure for small enterprise in technological innovation. In response to technological changes and gaining a competitive advantage in product quality and innovation, small and micro companies have to pay more attention to long-term innovation decisions rather than short-term operating profits. Facing the unfamiliar external environment, relatively short product cycle and highly technology elimination rate, small enterprises in the innovation process need to constantly examine and reorganize the existing resources, technology and capabilities, while constantly obtaining "energy" from enterprises in the social network. The stronger the technical environment turbulence, the easier it is for enterprises to acquire knowledge from the environment and realize the exchange of market demand information through inter-organizational knowledge transfer. At this time, small enterprises in low degree of network diversity, following the old path and relying on inertia, will enable enterprises to face "adaptation" and "inert", so that they cannot respond rapidly to the changes of the technical environment. The enterprises of high network diversity are reflected in the following advantages:

Network diversity can help enterprises to keep abreast of technology and new product changes, enhance awareness, in order to effectively develop technology, improve the product, innovate knowledge and integrate resources, to seize the technological changes and bring enterprise the "opportunity window ", thus improving innovation performance. For example, enterprises with high network diversity will establish inertia and pay attention to the new policy and new technologies, so that enterprises can find out the trajectory of technological change and avoid the great impact in the turbulence of the external technology environment; Network diversity the acquisition of complementary resources for innovation and promotes new knowledge and technology; Network 
diversity increases the flexibility of the enterprise strategy and improves the ability to resist risks[23].

To sum up, the following assumptions are put forward: $\mathrm{H} 2$ Technical environment turbulence reduces the negative impact of small enterprise social network diversity on innovation performance.

\section{Measurement of Variables}

\section{Measurement of Network Diversity}

In the case of the measurement of network diversity, refer to the previous literature and follows the practice of most scholars, using the diversity index--Blau index. The formula is shown in Eq.1:

$$
\text { Diversity }=1-\sum_{1}^{k} p_{i}^{2}
$$

Where " $\mathrm{P}$ " is the representative of the category, "I" is the proportion and " $\mathrm{k}$ " is the total number of categories. The Blau index is in the range 0 to 1 . The larger the value, the higher the diversity. This paper will code partner organizations in 7 parts which are the upstream and downstream enterprises (supply enterprises and demand enterprises), co-enterprises (competitive enterprises and complementary enterprises), universities and research institutions, government agencies, financial institutions, intermediaries and industry associations.

\section{Measurement of Innovation Performance}

Strategic management scholars emphasize the use of multiple indicators to measure innovative performance. This study uses the table shown in Table 1, reference to the view of Cheng DeJun et al.[9] and Qian XiHong et al.[10]. This scale emphasizes two key parts of innovation: Innovation quality and Innovation speed. During the course of the inquiry, surveyed the company's innovation which was compared with the average level of peers over the past two years. Because the topic option of the innovative performance measurement has both a 5-point Ricket scale form and a quantitative description, when final statistics is made, the quantity description form will be transformed into the corresponding Ricket scale form.

Table 1. Measurement scales for innovative performance

\begin{tabular}{|l|}
\hline \multicolumn{1}{|c|}{ Measure Items } \\
\hline $\begin{array}{l}\text { 1. In the past two years, your company's new product sales revenue accounted for the } \\
\text { proportion of total sales revenue }\end{array}$ \\
\hline $\begin{array}{l}\text { 2. In the past two years, the number of new products in your company accounted for the } \\
\text { proportion of total products }\end{array}$ \\
\hline $\begin{array}{l}\text { 3. In the past two years, your company uses new processes or new jobs to account for the } \\
\text { total product }\end{array}$ \\
\hline $\begin{array}{l}\text { 4. The past two years, your average annual new R \& D or renewal of technology than other } \\
\text { enterprises }\end{array}$ \\
\hline 5. Your company's current core technology level in the same industry level \\
\hline Title: Cheng DeJun et al., 2010; Qian XiHong et al., 2010 \\
\hline
\end{tabular}

\section{Measurement of Technical Environment Turbulence}

Based on the research of Jaworski[18], supplemented and modified by domestic and foreign researchers Terawatanavong[11], according to the research object and the change of environment, The Likert scale in the field of organizational behavior and strategic management is maturing. Based on the existing research, this study slightly tuned the measurement content according to the actual situation, and finally determined the form and content of the scale in the questionnaire, it is shown in Table 2. 
Table 2. Measurement of technical environment turbulence

\begin{tabular}{|l|}
\hline \multicolumn{1}{|c|}{ Measure Items } \\
\hline 1. Industry technology changes fast \\
\hline 2. Technological changes provide a lot of opportunities for development \\
\hline 3. Industry technology breakthrough gave birth to a series of new products \\
\hline 4. It is difficult to predict the future direction of technology development \\
\hline Title: Jaworski, 1993; Roger, 2003; Zhu ZhaoHui, 2007 \\
\hline
\end{tabular}

\section{Measurement of Control Variables}

In addition to network diversity, technical environment turbulence, there are many factors that affect the innovation performance of small enterprises. In order to ensure the reliability of the research results, this study chooses the enterprise scale, enterprise age, nature of ownership, industry and $\mathrm{R}$ $\&$ D intensity as control variables.

Enterprise Scale: Enterprise size is a factor that affects innovation performance. The discussion of firm size and enterprise innovation has never stopped. Some researchers believe that large-scale enterprises have a good resource endowment, can invest more innovative resources; some researchers believe that small-scale enterprises do not have the obstacles of managing inertia, more flexibility, have an advantage in innovation. In this study, the size of enterprises is measured by the number of employees, the number of employees in this questionnaire will be divided into four levels which are less than or equal to 10 people, 11-50 people, 51-100 people and 100 or more, respectively, with 1-4, which means that employees are full-time staff

Enterprise Age: The age of the enterprise is an important factor affecting the innovation performance of the enterprise. According to former research, enterprises operated longer often accumulate more industry resources and technical equipment, contribute to obtain external resources and information, and thus enhance the ability to innovate. The age of the firm is calculated as follows: Enterprise Age $=$ Year of the survey - Year of creation +1 . In the data processing, in order to maintain the linear relationship between age and innovation performance, the final age calculation results are logarithm before regression.

The Nature of Corporate Ownership: The nature of the ownership of the enterprise may affect the innovation performance. Therefore, according to the nature of the ownership of the enterprise, the small enterprises are divided into five categories: limited liability company, joint stock limited company, partnership enterprise, individual sole proprietorship and individual industrial and commercial household. Respectively, with1-5.

The Industry: According to the enterprise where the industry, small enterprises will be divided into four categories which are manufacturing, construction, information technology services and other services, respectively, with 1-4.

$\mathrm{R}$ \& D Strength: $\mathrm{R}$ \& $\mathrm{D}$ strength is an important determinant of innovation performance. Generally believed that the strength of enterprise $\mathrm{R} \& \mathrm{D}$ and business innovation was positively related. In this study, the intensity of $\mathrm{R} \& \mathrm{D}$, measured by the ratio of $\mathrm{R} \& \mathrm{D}$ investment to operating income, is divided into 5 levels which are less than $2 \%, 2 \%-5 \%, 6 \%-10 \%, 11 \%-20 \%$ and $20 \%$ or more, respectively, With 1-5.

\section{Questionnaire Design}

The questionnaire was composed of four parts. The first part is the basic situation questionnaire of the enterprise, including the year of creation, the number of employees, the annual sales income, the nature of the ownership of the enterprise, the proportion of the $\mathrm{R} \& \mathrm{D}$ investment to the business income; The second part is the basic situation of the enterprise social network, including the number of network subjects, the main contacting content among the subjects and the difficulties encountered; the third part is the measurement of the technical environment turbulence; the fourth part is the measurement of enterprise innovation performance. 
Questionnaire was issued for small enterprises located in the Beijing ZhongGuanCun Science and Technology Park, Software Park, Economic and Technological Development Zone, Chaoyang District Industrial Park and other high-end industrial park. Research object is mainly senior managers who master daily management of the small enterprise and primary information of innovation. Data collection is divided into three phases. The first stage is business interviews, stratified sampling survey of 15 small-micro scientific and technological enterprise in the park was conducted, semi-structured interviewed the person in charge. The visit was a formal research stage, surveyed a total of 380 enterprises in the industrial park and recycled 286, the recovery rate is $75.26 \%$. In the process of sorting out the questionnaire, rejected 20 cases of the unqualified questionnaires according to the research object. There are three criteria: one is not the definition of the small enterprise; the second is the questionnaires filled in incomplete or random questionnaires; the third is not the main person in charge of the enterprise filled the questionnaire. Due to the particularity of the research object, the small enterprises are strictly defined in the process of issuing and screening the questionnaire. Based on the application of different objects, government departments, industry associations, banking organizations and experts and scholars, respectively, define the scope of small enterprises.

June 18, 2011, China's Ministry of Industry and Information Technology, the National Development and Reform Commission and the Ministry of Finance jointly issued below, introduced the "issued on the issuance of small and medium-sized enterprises designated standard notice" (Ministry of Industry and Commerce (2011) number 300), officially brought small enterprises into the enterprise type, but also defined small enterprises from the number of employees, asset size, annual turnover and other aspect. The document expands the scope of application of the standard, makes coverage stronger, makes the indicators more flexible, pays more attention to the characteristics of the industry, and for the first time brings the "individual industrial and commercial households" into the reference implementation of the small enterprise. This study will organize it as an important criterion for screening small enterprises.

\section{Empirical Analysis}

\section{Reliability and Validity Analysis}

\section{Reliability Analysis}

Reliability refers to the degree of consistency or stability of the measured data, including re-test reliability, equivalent reliability and folding reliability, high reliability means that the ability to exclude random errors is strong. Consistency mainly examines the relationship between the questions of the questionnaire, check whether the items are measured the same content; stability refers to the questionnaire and the subjects are the same but the time to fill the questionnaire is different, in such condition repeat measuring the reliability of the results. In the empirical study, the internal consistency coefficient is generally used. The Cronbach's $\alpha$ is the most commonly used internal consistency coefficient, whose ranges from 0 to 1 , and the larger the coefficient, the higher the reliability, refer to Table 3 .

Table 3. Range of Cronbach's alpha

\begin{tabular}{|l|l|l|l|l|}
\hline Coefficient Range & \multicolumn{1}{|c|}{$\boldsymbol{\alpha} \geq \mathbf{0 . 9}$} & \multicolumn{1}{c|}{$\mathbf{0 . 9}>\boldsymbol{\alpha} \geq \mathbf{0 . 8}$} & $\mathbf{0 . 8}>\boldsymbol{\alpha} \geq \mathbf{0 . 7}$ & \multicolumn{1}{c|}{$<<\mathbf{0 . 7}$} \\
\hline $\begin{array}{l}\text { Judgment } \\
\text { Criteria }\end{array}$ & $\begin{array}{l}\text { Reliability is } \\
\text { high }\end{array}$ & $\begin{array}{l}\text { Reliability is } \\
\text { generally high }\end{array}$ & acceptable & $\begin{array}{l}\text { To be } \\
\text { rejected }\end{array}$ \\
\hline
\end{tabular}

The innovation performance and technical environment turbulence in this study are measured by multiple items and need to be tested for reliability. The results of SPSS20.0 are shown in Table 4. 
Table 4. Reliability analysis of innovation performance and technical environment turbulence

\begin{tabular}{|l|l|l|}
\hline \multicolumn{1}{|c|}{ Items } & \multicolumn{1}{|c|}{$\begin{array}{c}\text { Item - total score } \\
\text { correlation coefficient }\end{array}$} & \multirow{2}{*}{ Cronbach's $\alpha$} \\
\hline Technical Environment Turbulence 1 & 0.683 & \multirow{2}{*}{0.850} \\
\hline Technical Environment Turbulence 2 & 0.791 & \\
\hline Technical Environment Turbulence 3 & 0.697 & \multirow{2}{*}{0.809} \\
\hline Technical Environment Turbulence 4 & 0.592 & \\
\cline { 1 - 2 } Innovation Performance 1 & 0.424 & \\
\cline { 1 - 2 } Innovation Performance 2 & 0.509 & \\
\cline { 1 - 2 } Innovation Performance 3 & 0.725 & \\
\cline { 1 - 2 } Innovation Performance 4 & 0.682 & \\
\cline { 1 - 2 } Innovation Performance 5 & 0.647 & \\
\hline
\end{tabular}

It can be seen from the above table that the $\alpha$-coefficients of the technical environment turbulence and the innovation performance scale adopted in this study have reached the acceptable range of the social science scale, indicating that the measurement items of the scale are very consistent, it has high reliability.

\section{Distinguished Validity}

Before the exploratory factor analysis, the variables were subjected to KMO coefficient testing and Bartlett Test of Sphericity. The test results are shown in Table 5, the KMO value is 0.775, and the statistical value of the Bartlett sphere test is significantly at the 0.001 level, which is suitable for exploratory factor analysis.

Table 5. KMO and Bartlett tests for innovative performance and technical environment turbulence

\begin{tabular}{|c|c|c|c|}
\hline $\begin{array}{c}\text { KMO Sample } \\
\text { Adequacy Test }\end{array}$ & \multicolumn{3}{|c|}{ Bartlett Sphere Test } \\
\hline & Approximate Card Side & Degrees of Freedom & Significance \\
\hline .775 & 997.640 & 36 & 0.000 \\
\hline
\end{tabular}

Table 6. Exploratory factor analysis of innovative performance and technical environment turbulence

\begin{tabular}{|c|c|c|c|c|}
\hline \multirow{2}{*}{ Items } & \multicolumn{3}{|c|}{ Factor loadings } \\
\cline { 2 - 2 } & $\mathbf{1}$ & AVE & $\mathbf{2}$ & \multirow{2}{*}{ AVE } \\
\hline Technical Environment Turbulence 1 & 0.092 & & 0.822 & \multirow{2}{*}{0.686} \\
\hline Technical Environment Turbulence 2 & 0.082 & & 0.891 & \multirow{2}{*}{0.686} \\
\hline Technical Environment Turbulence 3 & 0.088 & & 0.832 & \\
\hline Technical Environment Turbulence 4 & -0.066 & & 0.764 & \\
\hline Innovation Performance 1 & 0.578 & & 0.023 & \\
\hline Innovation Performance 2 & 0.656 & & 0.161 & \\
\hline Innovation Performance 3 & 0.857 & \multirow{2}{*}{0.566} & -0.023 \\
\hline Innovation Performance 4 & 0.829 & & 0.020 & \\
\hline Innovation Performance 5 & 0.803 & & 0.024 & \\
\hline
\end{tabular}

On this basis, the principal component analysis method is used to extract the factors, and the maximum variance method is used to carry out the factor rotation. The maximum convergence iteration coefficient is 25 , and the results are shown in Table 6. Technical environment turbulence and innovation performance are classified into two factors, respectively. After the rotation, both two factor loadings are more than 0.5 , and the cumulative variance interpretation rate of the two factors is $62.6 \%$. 
The average variance extracted (AVE) is equal to mean square sum of factor loadings in the corresponding dimension.

The AVE values of innovation performance and technical environment turbulence are all greater than 0.5 , and the square root of AVE is greater than the correlation coefficient of 0.112 , which is in accordance with the reference standard, which indicate that the scale used in this study has good discriminant validity.

\section{Convergence Validity}

A validation factor analysis of technical environment turbulence and innovation performance is shown in Table 7.

Table 7. Fitting Index of Technical Environment Turbulence and Innovation Performance

\begin{tabular}{|c|c|c|c|c|c|}
\hline Fitting index & $\boldsymbol{x}^{\mathbf{2}} / \mathbf{d f}$ & RMSEA & GFI & AGFI & CFI \\
\hline Statistics & 1.833 & 0.056 & 0.964 & 0.934 & 0.979 \\
\hline Judgment criteria & $(2,5)$ & $<0.1$ & $>0.9$ & $>0.9$ & $>0.9$ \\
\hline
\end{tabular}

$x^{2} /$ dfrepresents the degree of fitting the model, and $x^{2} / \mathrm{df} \leq 2$ indicates that the fit is quite good; when $2<x^{2} / \mathrm{df} \leq 3$, the fit of the model is acceptable. RMSEA, means approximation error square root, is the ideal fit index. According to standards produced by former studies, as shown in Table 8 . GFI, AGFI and CFI are relative fitting indices, the greater their value, namely the closer to 1 , the better the fit.

Table 8. RMSEA Scope Criteria

\begin{tabular}{|c|c|c|l|}
\hline Coefficient range & RMSEA $\leq \mathbf{0 . 0 5}$ & $\mathbf{0 . 0 5}<\mathbf{R M S E A} \leq \mathbf{0 . 0 8}$ & $\mathbf{0 . 0 8}<\mathbf{R M S E A} \leq \mathbf{0 . 1}$ \\
\hline Judgment criteria & Fitability is quite good & Fitability is acceptable & Fit in general \\
\hline
\end{tabular}

Following the Gilbert model as model goodness test, the variables $x^{2} / \mathrm{df}$ is 1.833 , GFI is 0.964 , AGFI is 0.934, CFI is 0.979 and RMSEA is equal to 0.056. By judging the fit index, it shows that the two variables of technical environment turbulence and innovation performance have good convergence validity.

\section{Multiple Collinearity and Heteroscedasticity Test}

Multi collinearity refers to statistical problems arising from the high correlation of two variables or multiple variables. When there are multiple collinearity problems, the standard error is amplified and the estimation accuracy of the regression coefficient is reduced. The variance expansion factor VIF can be used to determine multi-collinearity problem, in general, VIF $\geq 10$, said that the independent variables have serious multiple collinearity. The VIF of this study is less than 2, so there is no multiple collinearity problem. Heteroscedasticity problem is a changing trend in the variance of the dependent variable with the change of the independent variable. It generally can be judged whether the heteroscedasticity exists by using the residual scatter plot, there is no heteroscedasticity to be tested in this study. Sequence correlation refers to the correlation of variables at different time points. The Durbin-Waston value is an important method to determine whether a sequence-related problem exists. In this study, random sampling of the cross-section data has no sequence-related problems in theory.

\section{Hierarchical Regression Analysis}

\section{The Main Effect Test}

According to the research hypothesis, the network diversity is the independent variable, the innovation performance is the dependent variable and the technical environment turbulence is the adjustment variable of this study. Among them, the innovation performance and technical environment turbulence use the average value of the measured items. First, the network diversity 
and innovation performance have a regression analysis, test the main effect.

In the first regression, the control variable, including enterprise age, enterprise size, the industry, the nature of ownership and R \& D intensity, were brought into the regression equation, and then join the variable innovation performance, have a regression. The results show that regression coefficient, both between the enterprise age and innovation performance and between industry and innovation performance, are not significant. And in terms of the small enterprises, the regression coefficient $\beta=0.125$, the significance level $p=0.008$; in terms of the nature of ownership, the regression coefficient $\beta=0.072$, the significance level $p=0.046$; the regression coefficient of the development intensity $\beta=0.197$, the significance level of the development intensity $p=0.000$, Indicating that the size of small enterprises, the nature of ownership and R \& D strength have a significant positive impact on innovation performance.

In the second regression, the control variables are still the age of the enterprise, the size of the firm, industry, the nature of the ownership and the strength of $\mathrm{R} \& \mathrm{D}$, and join the independent variable - network diversity, then dependent variable, namely, innovation performance. The results showed that the regression coefficient $\beta=-0.342$, the significance level $p=0.034$, indicated that social network diversity has a significant negative impact on innovation performance. H1 Small enterprise social network diversity has a negative impact on innovation performance has been proved.

\section{Regulatory Effect Test}

Table 9. Regression Analysis Results

\begin{tabular}{|c|c|c|c|c|c|c|c|c|}
\hline \multirow{2}{*}{ variables } & \multicolumn{2}{|c|}{1} & \multicolumn{2}{|c|}{2} & \multicolumn{2}{|c|}{3} & \multicolumn{2}{|c|}{4} \\
\hline & $\boldsymbol{\beta}$ & $\mathbf{P}$ & $\boldsymbol{\beta}$ & $\mathbf{p}$ & $\boldsymbol{\beta}$ & $\mathbf{p}$ & $\boldsymbol{\beta}$ & $\mathbf{p}$ \\
\hline Enterprise Age & 0.014 & - & 0.003 & - & 0.007 & - & 0.003 & - \\
\hline Enterprise Size & 0.125 & $* *$ & 0.130 & $* *$ & 0.142 & $* *$ & 0.139 & $*$ \\
\hline Industry & -0.038 & - & -0.037 & - & -0.029 & - & -0.035 & - \\
\hline $\begin{array}{l}\text { Nature of } \\
\text { Ownership }\end{array}$ & 0.072 & $*$ & 0.064 & - & 0.065 & - & 0.065 & - \\
\hline Strength of R \& D & 0.197 & $* * *$ & 0.205 & $* * *$ & 0.204 & $* * *$ & 0.205 & $* * *$ \\
\hline Network Diversity & & & -0.342 & $*$ & -0.337 & $*$ & -0.284 & - \\
\hline $\begin{array}{l}\text { Technical } \\
\text { Environment } \\
\text { Turbulence }\end{array}$ & & & & & 0.120 & $*$ & 0.138 & $* *$ \\
\hline $\begin{array}{l}\text { Network Diversity } \\
* \text { Technical } \\
\text { Environment } \\
\text { Turbulence }\end{array}$ & & & & & & & 0.309 & $*$ \\
\hline R Square & \multicolumn{2}{|l|}{0.188} & \multicolumn{2}{|l|}{0.202} & \multicolumn{2}{|l|}{0.220} & \multicolumn{2}{|l|}{0.233} \\
\hline Adjusted R Square & \multicolumn{2}{|l|}{0.172} & \multicolumn{2}{|l|}{0.183} & \multicolumn{2}{|l|}{0.199} & \multicolumn{2}{|l|}{0.209} \\
\hline F Value & \multicolumn{2}{|c|}{$12.025(.000)$} & \multicolumn{2}{|c|}{$10.915(.000)$} & \multicolumn{2}{|c|}{$5.381(.000)$} & \multicolumn{2}{|c|}{$4.136(.000)$} \\
\hline
\end{tabular}

Note: * means $\mathrm{P}<0.05$, ** means $\mathrm{P}<0.01$, *** means $\mathrm{P}<0.001$.

According to the study concluded by Wen ZhongLin[12], hierarchical regression analysis is an effective way to test the interaction effect. Regression analysis was performed using the steps in the regulatory effect analysis method, the regression results are shown in Table 9. Since this study involves an interactive items, the data (network diversity and technical environment turbulence) are 
centrally processed before regression. Then proceed to the multi-collinearity test, the variance expansion factor (VIF) is between 1-2, indicating that there is no such problem, the analysis results are reliable. According to the recommendations of Wen Zhonglin[12], the variables were put into the regression model in turn. In the third regression, the control variables are still the age of the enterprise, the size of the firm, the nature of the ownership, industry and the intensity of R \& D. On the basis of the independent variable of network diversity, the regulatory variable technical environment turbulence and the dependent variable innovation performance are added in turn to have a regression analysis. The empirical results show that the regression coefficient $\beta=0.120$, the significance level $p=0.014$, indicating that the technical environment turbulence has a significant positive impact on innovation performance. In the fourth regression, on the basis of the third regression, adding the interactive items between the independent variable network diversity and the dependent variable technical environment turbulence to return. The results showed that the regression coefficient $\beta=0.309$ and the significance level $p=0.043$, indicating that the interaction between network diversity and technical environment turbulence have a significant effect on innovation performance. H2 Technical environment turbulence weakened that the small enterprise social network diversity on the negative impact of innovation performance to be verified.

\section{Research Conclusions and Prospects}

\section{Research Conclusions}

From the number of network partners, there are 168 enterprises have cooperative relationships with 1-10 network subjects; 55 enterprises with 11-20 network subjects; 32 enterprises with 21-50 network subjects; 11 enterprises with more than 50 network subjects. In the 266 small enterprises surveyed, almost all of the subjects are directly connected with the government departments. There are 44 enterprises have cooperative relationships with 2 types of network subjects; 36 enterprises with 3 types of network subjects; 39 enterprises with 4 types of network subjects; 34 enterprises with 5 types of network subjects; 39 enterprises with 6 types of network subjects; 74 enterprises with 7 types of network subjects.

Small enterprise social network diversity has a negative impact on innovation performance: In the regression model, the control variables: enterprise age, enterprise scale, industry, ownership nature, R \& D intensity and independent variable network diversity were added, and regression was carried out with the dependent variable innovation performance. It was found that the regression coefficient $\beta=-0.342$ was negative and $p=0.034$. Indicating that the small enterprise social network diversity has a negative impact on innovation performance.

The technical environment turbulence weakened the small enterprise social network diversity on the negative impact of innovation performance: In the hierarchical regression, on the basis of adding the control variables: enterprise age, enterprise scale, industry, ownership nature, $\mathrm{R} \& \mathrm{D}$ intensity and independent variable network diversity, and adding technical environment turbulence and the interactive items between technical environment turbulence and network diversity to have a regression. It was found that the regression coefficient $\beta=0.309$ was positive and $p=0.043$. Indicating that the technical environment turbulence weakened the small enterprise social network diversity on the negative impact of innovation performance.

\section{Policy Recommendations}

\section{Small Enterprise Management Recommendations}

Small enterprises should pay attention to innovation which is important to its long-term development. In today's era of rapid economic development, business competition is fierce, small enterprises are facing enormous pressure to survive. Due to the huge risk of innovation, small enterprises tend to pay more attention to short-term operating profit while neglecting the competitive advantage of enhancing innovation ability in the case of low expected return on innovation. Facts have proved that the rapid development of science and technology today, only innovation is the long-term plan of 
development. Small enterprises should actively create culture and atmosphere of enterprise innovation, to achieve transformation and upgrading.

Small enterprises should enhance the regulatory capacity of the network. Empirical studies have shown that network diversity is not "much better". Small enterprise network diversity has a negative impact on innovation performance, so blind pursuit of diversity without focus on quality, is not desirable. Therefore, small enterprises should enhance the network management capacity, take care of process of choosing the network partners: network cooperative relationships are complex and conflict is inevitable, so strive to create a win-win cooperation and innovation environment, to avoid the interest confrontation of zero sum competition. Not only to consider the changes in the technical environment and the complementarity of knowledge and resources in network, but also to analyze their own factors (size, absorptive capacity and network monitoring experience), balancing the relationships between the number of partners and their own attribute, reasonable controlling the quantity of the network subjects, The advantage is that small enterprises can cooperate with the right amount of partners to resist the risks posed by the technical environment uncertainty, but also to control the quality of cooperation with partners and improve management efficiency.

\section{Policy Recommendations for Promoting Development of Small enterprises}

The government should guide small enterprises to enhance the sense of innovation. Compared with the developed countries, small enterprises' potential in the development of innovation has not yet fully play in China. Under the new economic norm, the government should focus on training small enterprises innovation awareness, and guide small enterprises to release the vitality of innovation for China's economic development help.

To play the influence of the government, in order to clear the hinder on the road to innovation. Small enterprises innovation activities will inevitably encounter market failure and lack of investment, small enterprise need government intervention to help them to achieve innovation goals. Reduce what small enterprises worry about in innovation by reducing tax burden to a certain extent; simplify the approval process allows enterprises to use more energy in the development and innovation, rather than "run around". The government should reduce the tax burden, simplify the examination and approval procedures, make supervise and management transparent and eliminate the obstacles to the innovation and development of small enterprises.

To create a good regional innovation environment. Innovation is an interactive learning process that has social and regional roots. In particular, the small enterprises with relatively weak innovation ability need to use the external knowledge resources effectively through the learning activities, and the dependence on the regional innovation environment is very strong. Information asymmetry and lack of competition are still impede innovation and development of small enterprises. What small enterprises ask government for shows that the current innovation and entrepreneurship environment of small enterprise to be further optimized. In recent years, the state launched a series of policies, and strive to create a policy environment between small-micro enterprises and large-medium sized enterprises to share social resources. But we must also see that there is still a long way to go to its successful landing from the introduction of the policy.

To build a small enterprise innovation public service platform. Reasonable structured, full-featured and well-structured small enterprise innovation public service platform, through the optimization of the allocation of policies, funds, personnel, information and so on, effectively avoid small enterprise social network construction and regulatory capacity deficiencies, to create "Widespread entrepreneurship and innovation" atmosphere.

\section{Research Outlook}

Through the theoretical and empirical research, this paper has made some conclusions on the relationship between the diversity of social network and the innovation performance of small enterprises, and achieved certain results. However, due to lack of research experience, research resources and research constraints and other reasons, there are some deficiencies in research, on the relationship between social network diversity and innovation performance, there is still a lot of room for research in the future. 
The survey sample of this study is concentrated in Beijing, but the development of enterprises in various regions of the country exist gaps, so the national universality of the conclusion remains to be further explored. In future studies, scholars can sample in different provinces and cities, realize the generalization of research results.

In this study, we selected the technical environment turbulence as the adjustment variables, and the result also proved that it has a regulatory role. However, whether there are other regulatory variables between the social network diversity and the innovation performance, it needs to be further explored in the future.

\section{Acknowledgements}

First and foremost, I would like to show my deepest gratitude to my supervisor, Dr. Tao QiuYan, a respectable, responsible and resourceful scholar, who has provided me with valuable guidance in every stage of the writing of this paper. Without her enlightening instruction, impressive kindness and patience, I could not have completed my paper. Her keen and vigorous academic observation enlightens me not only in this paper but also in my future study.

I shall extend my thanks to Mrs. He for all her kindness and help. I would also like to thank all my teachers who have helped me to develop the fundamental and essential academic competence. My sincere appreciation also goes to the teachers and students from Management College in Beijing Union University, who participated this study with great cooperation.

Last but not least, I'd like to thank all my friends, especially my three lovely roommates, for their encouragement and support.

This research was financially supported by the National Science Foundation, and this paper is the research result of the project named Research on Social Capital, Knowledge Management and Growth of Small and Medium-sized Enterprises with Science and Technology, whose Project code is 11103AE1601

\section{References}

[1] Goerzen, A., Beamish, P. W. The Effect of Alliance Network Diversity on Multinational Enterprise Performance [J]. Strategic Management Journal, 2005, 26(4): 333-354.M. Young, The Technical Writer's Handbook. Mill Valley, CA: University Science, 1989.

[2] Beers, C. V., Zand, R\&D Cooperation, Partner Diversity, and Innovation Performance: An Empirical Analysis [J]. Journal of Product Innovation Management, 2014, 31(2):292-312.

[3] Cajueiro, D. O., Tabak, B. M. The role of banks in the Brazilian interbank market: Does bank type matter? [J]. Physica A Statistical Mechanics \& Its Applications, 2008, 387(27):6825-6836.

[4] Tiwana, A. Do Bridging Ties Complement Strong Ties? An Empirical Examination of Alliance Ambidexterity [J]. Strategic Management Journal, 2008, 29(3): 251-272.

[5] Sun GuoQiang, Shi HaiRui. Advances in Negative Effects Theory of Network Organization [J]. Future and Development, 2009, 30(11):31-34.

[6] Wu ShaoTang, Li YanPing. Is the network of enterprise alliance diversification conducive to cooperation and innovation? - A regulated mediating effect model [J]. Nankai Business Review, 2014, 17(3): 152-160.

[7] Chi RenYong. Research on Node Linkage and Efficiency Evaluation of Regional Small Enterprise Innovation Network [J]. Management World, 2007, (1):105-112.

[8] ChaoHui, Chen Jin. Synergy and Dynamics of Exploratory and Excavated Learning: Empirical Research [J]. Science Research Management, 2008, 29(6): 1-9. 
[9] Cheng DeJun, Song Zhe, Wang BeiBei. Cognitive Trust or Emotional Trust: The Impact of High Participation in the System on Organizational Innovation Performance [J]. Business Management Journal, 2010, (11): 81-90.

[10]Qian XiHong, Yang YongFu, Xu WanLi. Enterprise Network Location, Absorptive Capacity and Innovative Performance - An Interactive Effect Model [J]. Management World, 2010, (5): 118-129.

[11]Terawatanavong, C., Whitwell, G. J., Widing, R. E., O'Cass, A. Technological turbulence,supplier market orientation, and buyer satisfaction [J]. Journal of Business Research, 2011, 64(8): 911-918.

[12] Wen ZhongLin, HouJieTai, Zhang Lei. Comparison and Application of Regulation Effect and Mediating Effect [J]. ActaPsychologicaSinica, 2005, 37(2): 268-274.

[13]Zhang Yan, Wei Jiang. R \& D Partner Diversity and Innovation Performance - The Regulatory Effect of R \& D Cooperation Experience [J]. Science of Science and Management of S. \& T, 2015. 36(11): 103-111.

[14]Fang Gang. Research on the Mechanism of Network Competence Structure and the Performance of Enterprise Innovation [J]. Studies in Science of Science, 2011, 29(3):461-470.

[15] Wu JiangTao. Research on the innovation of Science and technology micro-Financial system [J]. Science \& Technology Progress and Policy, 2012, 29(19): 103-106.

[16]Qin Yao. How can commercial banks support the development of small enterprises of science and technology [J].Contemporary Finance, 2012, (3): 40-41.

[17]Liu Luo, Chen ShuWen. Testing of Job Performance Structure Model of Small Enterprise Loan Account Manager [J]. Scientific Management Research, 2012, 30(2): 75-79.

[18]Jaworski, Kohli.Measure of Market Orientation [J].Journal of Marketing, 1993, 30(4)467-477.

[19]Granovetter.The Strength of Weak Ties: A Network Theory Revisited [J]. Sociological Theory, 1983 , 1 (6) :201-233

[20] Granovetter. Economic Action and Social Structure: The Problem of Embeddedness [J]. American Journal of Sociology, 1985, 91(3): 481-510.

[21]Burt. Structural Holes: The Social Structure of Competition [M].1992.

[22]Reagans, Zuckerman. Networks, diversity and performance: The social capital of R\&D units [J]. INFORMS, 2001, 12(4):502-517.

[23]Chi RenYong. Forming and developing phases of small \& medium enterprise innovation network: A case of Shaoxing textile industrial cluster [Z]. Proceedings of the Eighth West Lake International Conference on SMB (2006)1130-1136.

[24]Higgins, Kram. Reconceptualizing Mentoring at Work: A Developmental Network Perspective [J]. Academy of Management Review, 2001, 26(2):264-288. 